\title{
DA RELAÇÃO ENTRE OS GRAUS DE CONHECIMENTO E AS CAPACIDADES DE REPRESENTAÇÃO EM KANT
}

\author{
Olavo Calábria Pimenta*
}

\begin{abstract}
RESUMO
Na Lógica Jäsche encontramos uma descrição dos graus do conhecimento segundo Kant, que em ordem crescente seria a seguinte: representarse, perceber, saber, conhecer, entender, discernir e compreender ( Log: 09, 64-65), com a seguinte advertência no quarto nível: "os animais também sabem dos objetos, mas não os conhecem" (Log: 09, 65). É bem conhecida a definição kantiana de conhecimento enquanto resultado da aplicação de conceitos do entendimento aos objetos da intuição sensível. Também conhecemos sua tese de que as "categorias são conceitos que prescrevem leis a priori aos aparecimentos, por conseguinte à natureza, como conjunto de todos os aparecimentos" ( $K r V:$ B163). Buscamos analisar neste artigo a referida série ordenada dos graus de conhecimento mediante a consideração dos papéis específicos que Kant atribui a cada uma das capacidades de representação que compõem o aparelho cognitivo humano e que colaboram para a construção do conhecimento, conforme descrições feitas principalmente no âmbito da $K r V$ (AA 03 e 04), Anthropologie (AA 07), Logik (AA 09) e Vorlesungen (AA 24: ff.). Sustentamos a posição de que estes distintos graus de conhecimento se devem à crescente complexidade operacional proporcionada, primeiramente, pelos sentidos, que recebem de modo meramente passivo o múltiplo desconectado da intuição, para então elaborar espontaneamente pela imaginação um conjunto de sínteses subjetivamente unificadas, construindo aparecimentos [Erscheinungen] mediante a formação de imagens no espaço e a associação de intuições no tempo, para, finalmente, e com a colaboração do entendimento que prescreve leis à natureza $(\mathrm{KrV}$ : B165, B163, B159), elaborar o conhecimento empírico dos objetos da experiência, ou fenômenos [Phaenomena], pela reunião objetiva da multiplicidade dos aparecimentos sob regras de unidade intelectuais.
\end{abstract}

\footnotetext{
* Doutor em Filosofia pela Universidade Federal de Minas Gerais (UFMG). Professor de Filosofia Moderna na Universidade Federal de Uberlândia (UFU). Residente em pósdoutorado junto ao "Grupo de Estética e Filosofia da Arte" da UFMG.

E-mail: calabria@defil.ufu.br
} 
Palavras-chave: Graus de conhecimento. Capacidades do ânimo. Operações cognitivas. Entes não racionais.

\begin{abstract}
At the Jäsche Logic we find a description of the degrees of knowledge according to Kant, which in ascending order would be as follows: to represent, to perceive, to be acquainted, to know, to understand, to have insight and to comprehend (Log: 09, 64-65), with the following warning at the fourth level: "the animals also be acquainted with objects, but do not know them" (Log: 09, 65). It is well known the Kantian definition of knowledge as a result of the application of concepts of the understanding to objects of sensible intuition. We also know his thesis that the "categories are concepts which prescribe laws a priori to appearances, therefore to nature, as the set of all appearances" ( $K r V:$ B163). We aim to analyze in this article that ordered series of levels of knowledge by considering the specific role Kant assigns to each of the faculties of representation that compose the human cognitive apparatus and that contribute to the construction of knowledge as descriptions made principally at the $\mathrm{KrV}$ (AA 3:04), Anthropologie (AA 07), Logik (AA 09) and Vorlesungen (AA 24: ff.). We hold the position that these different levels of knowledge are due to increasing operational complexity provided, first, by the senses, so they get the disconnected multiple of intuition in a merely passive way, and then by imagination that develop spontaneously a set of synthesis subjectively unified, building appearances [Erscheinungen] through the formation of images in space and association intuitions in time, to finally and with the collaboration of the understanding, which prescribes laws to nature ( $K r V: \mathrm{B} 165, \mathrm{~B} 163, \mathrm{~B} 159)$, to elaborate the empirical knowledge of the objects of experience or phenomena [Phaenomena], by the objective reunion of the multiplicity of appearances under rules of intellectual unity.
\end{abstract}

Keywords: Degrees of knowledge. Mind faculties. Cognitive operations. Not rational beings.

Nas Preleções de Lógica (Log: AA 09, 1-150), Kant nos apresenta uma série ordenada dos graus de conhecimento segundo uma complexidade crescente que, de acordo com ele, diz respeito em geral ao seu "conteúdo objetivo" (Log: AA 09, 64). Para nós de língua portuguesa, 
ainda encontramos ali um adendo de não pouco valor, pois são sugeridas determinadas expressões latinas como correspondendo a diversos termos utilizados. Como nossas considerações subsequentes estarão referindose amiúde a esta série, reproduzimo-la a seguir integralmente, indicando também entre colchetes algumas expressões originais que Kant utilizou para cada um dos graus:

O primeiro grau do conhecimento é: o representar-se algo [sich etwas vorstellen];

O segundo: representar-se algo com consciência ou perceber [wahrnehmen] (percipere);

O terceiro: saber [kenenn] algo (noscere) ou representar-se algo pela comparação com outras coisas, tanto segundo a identidade como segundo sua diversidade;

O quarto: saber algo com consciência, isto é, conhecer [erkennen] (cognoscere); os animais também sabem dos objetos [Gegenstände] mas não os conhecem.

O quinto: entender [verstehen] algo (intelligere), isto é, conhecê-lo pelo entendimento graças a conceitos ou concebê-lo (concipiren). Difere muito do compreender [Begreifen]. Há muito que pode ser concebido (concipiren), embora não possa ser compreendido. Como, por exemplo, um perpetuum mobile, cuja impossibilidade é demonstrada pela Mecânica.

O sexto: discernir [einsehen] (perspicere) ou conhecer algo pela razão. Em poucas coisas conseguimos nos elevar até aí e nossos conhecimentos são em número cada vez menor quanto mais desejamos aperfeiçoar-lhes o conteúdo.

O sétimo, enfim: compreender [begreifen] algo (comprehendere), isto é, conhecê-lo pela razão ou a priori, naquele grau que é suficiente ao nosso propósito. - Pois toda a nossa compreensão é apenas relativa, isto é, bastante para um certa intenção, e de modo algum compreendemos absolutamente. Nada pode ser melhor compreendido do que o que o matemático demonstra, por exemplo, que todas as linhas do círculo são proporcionais. E, não obstante, ele não compreende como ocorre que uma figura tão simples tenha tais propriedades. O campo do entender ou do entendimento é, por isso, em geral, muito maior do que o campo do compreender e da razão. (Log: AA 09, 64-65, grifos nossos). 
Nosso objetivo neste trabalho é avaliar em que medida as descrições kantianas sobre as capacidades de representação, com as propriedades específicas que possuem e correspondentes tarefas que lhes são próprias, pode explicar e justificar a estrutura desta classificação ordenada de graus do conhecimento e as distinções entre os diferentes níveis, visto que, para Kant, tais conhecimentos devem justamente resultar das operações realizadas pelas capacidades do ânimo, isoladamente ou em colaboração. Neste sentido, buscaremos não apenas identificar as especificidades de cada um destes graus, como também compreender os motivos pelos quais cada um ocupa seu lugar determinado nesta série.

\section{As capacidades de representação na filosofia kantiana}

Kant sustenta que a discussão sobre as capacidades do ânimo não pertence essencialmente à finalidade principal de sua filosofia, já que a tarefa da razão pura consiste no fundo em perguntar sobre a possibilidade os juízos sintéticos a priori ( $K r V$ : B19) e não sobre como é possível a própria faculdade de pensar ( $K r V:$ A17). Mesmo assim, ele admite que a menção a tais capacidades, cada uma lidando com determinados tipos de representações e executando tarefas específicas, não deixa de desempenhar um papel de grande importância na sua argumentação em geral, pois serve de apoio ao esclarecimento e articulação do projeto essencial de determinar as condições e limites do conhecimento a priori, determinando "o que e até onde o entendimento e a razão podem conhecer" ( $K r V:$ A17).

Mediante o cotejo de trechos de várias obras e das operações articuladas que desempenham na execução colaborativa de múltiplas tarefas, podemos derivar uma descrição satisfatória das capacidades do ânimo [Gemüt] proposta por Kant. Na primeira Crítica aparecem expressões como faculdade de conhecimento [Erkenntniskraft] (CRP $\mathrm{B} 317,351$, etc.) e capacidade de representação [Vorstellungsfähigkeit] (CRP B 34, 61, 150, etc.) para designar o conjunto das capacidades do ânimo envolvidas na produção do conhecimento, apresentando duas fontes [Quellen] (ou troncos [Stämme]) de conhecimento: 
O nosso conhecimento provém de duas fontes fundamentais [Grundquellen] da mente, das quais a primeira consiste em receber as representações (a receptividade [Rezeptivität] das impressões) e a segunda é a capacidade de conhecer um objeto mediante estas representações (espontaneidade [Spontaneität] dos conceitos) (KrV: A50/B74).

Por estar fundada na receptividade ou espontaneidade de adquirir representações, Kant considera que esta é uma divisão metafísica do ânimo (Lóg: AA 09, 36), sendo a sensibilidade uma fonte receptiva de representações intuitivas dadas, enquanto que o entendimento é uma fonte espontânea de representações discursivas pensadas:

Como introdução ou advertência parece necessário dizer apenas que há dois troncos [Stämme] do conhecimento humano que talvez brotem de uma raiz comum, mas desconhecida a nós, a saber, sensibilidade [Sinnlichkeit] e entendimento [Verstand]: pela primeira, objetos sãonos dados, mas pelo segundo são pensados ( $K r V$ : A15/B29).

A possibilidade que nosso ânimo possui de assumir tanto um caráter receptivo como um caráter espontâneo é ratificada pelo seguinte trecho da Antropologia de um ponto de vista pragmático (1798), em que são identificados respectivamente com a passividade ou a atividade destes troncos:

Com respeito ao estado das representações, meu ânimo ou é ativo [handelnd] e mostra possuir uma faculdade [Vermögen] (facultas), ou é passivo [leidend] e consiste em uma receptividade [Empfänglichkeit] (receptivitas) (Anth: AA 07, 140).

E ainda:

Representações, com respeito às quais a mente se conduz passivamente, ou seja, pelas quais o sujeito é afetado [affiziert] (que pode afetar-se a si mesmo ou ser afetado por um objeto), pertencem à capacidade de conhecimento sensivel [sinnlichen Erkenntnisvermögen], enquanto que aquelas que encerram um mero agir [Tun] (o pensar) pertencem à de conhecimento intelectual [intellectuellen] (Anth: AA 07, 140). 
$\mathrm{Na}$ sequência imediata deste trecho encontramos a declaração de que a receptividade está associada às representações intuitivas dos sentidos, enquanto que a espontaneidade, às representações discursivas do pensamento:

Aquela se chama também capacidade de conhecimento inferior e esta, porém, de superior. Aquela tem o caráter [Character] de passividade [Passivität] que é própria das sensações do sentido interno [inneren Sinnes]; esta, o [caráter] da espontaneidade [Spontaneität] que é próprio da apercepção, isto é, a pura consciência da ação que constitui o pensar e pertence à lógica (um sistema das regras do entendimento), assim como aquela pertence à psicologia (um inventário de todas as percepções internas submetidas a leis naturais), e funda a experiência interna (Anth: AA 07, 140-1).

Esta atribuição de espontaneidade ao entendimento e de receptividade à sensibilidade carece de detalhamento. Mostramos como resultado de pesquisas anteriores (CALÁBRIA, 2011) que Kant concebe a faculdade de imaginação como lidando exclusivamente com representações intuitivas e, por isso, consistindo numa parte da sensibilidade. Porém, mesmo assim, vamos mostrar agora que ela possui o caráter de espontaneidade, exercendo ativamente, e não passivamente, suas operações de síntese unificadas da multiplicidade sensível.

Inicialmente, notemos que a detalhada descrição da faculdade da imaginação [Einbildungskraft] fornecida por Kant na Antropologia não apenas ratifica que ela pertence mesmo à sensibilidade, como ainda nos informa sobre o que a distingue do sentido $[$ Sinn]:

A sensibilidade [Sinnlichkeit] na capacidade do conhecimento (a capacidade das representações na intuição) contém duas partes: o sentido [Sinn] e a faculdade da imaginação [Einbildungskraft]. A primeira é a capacidade de intuição na presença do objeto e, a segunda, também sem a presença deste (Anth: AA 07, 152).

Este trecho surpreende não apenas pela inusitada inserção da imaginação como sendo uma parte da sensibilidade, mas em particular 
pela forma categórica com que esta caracterização é feita. Dentre as quatro concepções modelares sobre a imaginação que os intérpretes de Kant têm lhe atribuído desde então, representadas pelas posições de Heidegger (1929), Makkreel (1990), Longuenesse (1993) e Caimi (2008), apenas a de Heidegger é sensível ao espírito destas declarações de Kant ${ }^{1}$. Além disso, este trecho nos informa que a imaginação difere da outra parte da sensibilidade, o sentido, por ser capaz de fornecer uma apresentação na intuição também sem a presença do objeto.

Apesar de Kant ter frisado o termo "sem", que naturalmente expressa a distinção fundamental entre imaginação e sentido, já que este somente fornece o múltiplo da intuição com a presença do objeto, entendemos como promissor atentarmos na presença neste trecho do termo "também" [auch]. De fato, não se limitando a repetir um procedimento comum na história da filosofia, o de identificar a imaginação como a capacidade de proporcionar-nos representações sensíveis na ausência do objeto, Kant inova proferindo uma posição que ainda hoje raramente lhe é creditada e atribuída, alegando que a imaginação também contribui para que intuições nos sejam apresentadas na presença do objeto. Como a imaginação é considerada também participante da apresentação de intuições na presença do objeto, e sendo esta uma característica costumeiramente atribuída ao sentido, é natural que Kant se sinta na obrigação de esclarecer qual seria então a diferença entre o papel desempenhado pelo sentido e o papel desempenhado pela imaginação neste caso.

Temos uma boa pista disto em nota da primeira Crítica em que Kant, referindo-se à atividade da imaginação ao sintetizar o múltiplo da intuição na etapa designada de "apreensão", polemiza com os psicólogos de sua época:

Que a imaginação seja um ingrediente necessário da própria percepção, certamente ainda nenhum psicólogo pensou. Isto acontece, em parte,

1 Em nossa tese de doutorado (CALÁBRIA, 2011) mostramos que embora a interpretação de Heidegger seja a única, dentre as mencionadas, que adequadamente se concilia à concepção kantiana da imaginação como parte da sensibilidade, ele peca ao extrapolar a intenção e a letra de Kant, ao sustentar que ela seria a raiz comum [gemeinsame Wurzel] entre entendimento e sensibilidade (HEIDEGGER, 1929, 134 e ss.). 
porque se limitava essa faculdade apenas às reproduções, e em parte, porque se acreditava que os sentidos nos forneciam não só impressões, mas também as encadeavam e conseguiam formar imagens dos objetos, o que, sem dúvida, além da receptividade das impressões, ainda exige algo mais, a saber, uma função que as sintetize (KrV: A120, n.).

Podemos sem dificuldade deduzir destas palavras qual é a parte que cabe ao sentido e qual cabe à imaginação durante a apresentação de intuições na presença do objeto. O que Kant sustenta é que, para termos qualquer percepção na presença do objeto, é necessário que o sentido participe com sua capacidade de ser afetado, recebendo assim, de modo passivo, a multiplicidade dada na intuição, sempre sob as condições formais do espaço e do tempo. Como o sentido é mera receptividade, a partir exclusivamente dele não pode resultar nenhum conjunto de multiplicidades intuitivas reunidas, mas somente "percepções diversas, dispersas e isoladas" ( $K r V$ : A120). Isto naturalmente ainda não nos proporciona qualquer objeto da intuição sensível, que, como tal, precisa conter nele reunida uma multiplicidade sensível. Na referida passagem da primeira Crítica, em que Kant polemiza com os psicólogos, ele declara o caráter espontâneo da imaginação nos seguintes termos:

Há, pois, em nós uma capacidade ativa [tätiges] da síntese deste múltiplo, que chamamos imaginação [Einbildungskraft], e a sua ação [Handlung], que se exerce imediatamente nas percepções, designo por apreensão" (KrV: A120).

Então, cabe justamente à imaginação, ainda na presença do objeto, 0 ato de elaborar a reunião da multiplicidade intuitiva num todo sensivelmente unificado. O que Kant se vangloria de ter feito, e que considera colocá-lo à frente dos psicólogos, é compreender que a multiplicidade meramente recebida pelo sentido e, portanto, ainda desconectada, não pode alcançar o nível de complexidade de um objeto da intuição. A representação de tal objeto é essencialmente bem elaborada e, para surgir, necessita ser construída espontaneamente pela reunião da multiplicidade dada num todo 
unificado. Na Antropologia (1798), Kant nos explica que esta operação é precisamente a formação de figuras no espaço operada pela capacidade autora sensivel de formação ou imaginatio plastica (Anth.: AA 07, 174-5).

Num trecho das Preleções que reproduzimos a seguir, Kant alerta para o fato de que a imaginação, mesmo estando apta a operar espontaneamente ${ }^{2}$ sobre as representações da intuição sensível, somente pode fazê-lo com a condição de que anteriormente tenhamos recebido afecções provenientes dos sentidos:

Por exemplo, a representação que eu vejo; e, além disso, a representação do azedo, do doce etc. são representações do próprio sentido. Mas se eu me re-apresento [vergegenwärtige] uma casa, que vi anteriormente, então a representação agora provém da mente; mas, no entanto, sobre a condição de que o sentido seja afetado previamente por este objeto. Tal conhecimento sensível que provém da espontaneidade [Spontaneität] da mente chama-se conhecimento da faculdade de formar [bildenden Kraft]; e o conhecimento que provém mediante a impressão dos objetos chama-se representação do próprio sentido (Vorl: AA 28, 230).

Quer dizer, a imaginação não tem a capacidade de criar as representações intuitivas elementares com as quais lida (as impressões ou as formas puras do espaço e tempo), mas simplesmente as elabora a partir do momento em que nos forem dadas, pois, embora nosso conhecimento não se origine completamente da experiência, ele somente começa com ela, e o ânimo precisa ser despertado e colocado em exercício pelos objetos que afetam a nossa capacidade de conhecer $(K r V: \mathrm{B} 1)$.

Analogamente ao que fez em relação à sensibilidade, também no que diz respeito ao segundo tronco de nossa capacidade de representação, relacionado às faculdades intelectuais, Kant apresenta suas subdivisões:

2 Estamos convictos de que neste trecho Kant está efetivamente se referindo à faculdade da imaginação quando menciona as representações sensíveis (intuições) provenientes da própria mente, tanto devido à alusão feita à representação da memória, que é explicitamente identificada como uma das atividades da imaginação (cf. Anth: AA 07, 182-5), mas também devido à expressão "faculdade de formar" [bildenden Kraft] que é bem característica de descrição kantiana da imaginação (Vorl: AA 28, 230-8 e Anth: AA 07, 174 e ss., entre outras). 
Mas toma-se a palavra entendimento [Verstand] também em um significado particular: aí ele mesmo é subordinado, como membro de uma divisão, com dois outros [membros], ao entendimento [Verstand] em sentido universal [allgemeiner], e aí subsiste a capacidade superior de conhecimento (materialiter, isto é, considerada não para si sozinha, mas sim em relação ao conhecimento dos objetos) feita de entendimento, faculdade do juízo e razão (Anth: AA 07, 196-7).

Em outras palavras, o que Kant está fazendo é utilizar o termo "entendimento" [Verstand] em dois sentidos, um em "sentido universal" e outro, em sentido "particular". O entendimento em sentido particular consiste na faculdade das representações conceituais que, na primeira Crítica, foi objeto da primeira etapa de investigação na "Analítica Transcendental" e de onde se originam os conceitos puros ou categorias. Ao lado desta faculdade situam-se a faculdade do juízo [Urteilskraft] e a razão [Vernunft], que são tratadas também na primeira Crítica, em especial na segunda parte da "Analítica Transcendental" e na "Dialética Transcendental", respectivamente. Já o entendimento [Verstand] em sentido universal, ou capacidade superior de conhecimento, nada mais é do que o nome que se dá ao conjunto destas três faculdades intelectuais.

Kant distingue as faculdades intelectuais das capacidades intuitivas, chamando-as, respectivamente, de superiores e inferiores. Não devemos, porém, concluir disso que as faculdades intelectuais sejam indispensáveis e as sensíveis, não. Pelo contrário, Kant é enfático ao afirmar que ambas são imprescindíveis para a construção do conhecimento objetivo ( $K r V$ : A51/ B75 e A258/B314, p. ex.). Aqui, o critério de distinção entre as faculdades superiores (intelectuais) e as inferiores (sensíveis) parece ser apenas a maneira pela qual executam suas tarefas que em conjunto resultam na construção do conhecimento, seja, no caso da sensibilidade, simplesmente recebendo e livremente sintetizando a multiplicidade da intuição, isto é, de forma apenas subjetiva, enquanto que, no caso do intelecto, suas operações sobre esse material sensível são elaboradas de forma orientada, submetendo a multiplicidade da intuição a regras discursivas de unificação, ou seja, de forma objetiva: 
É também costume chamar a sensibilidade de faculdade inferior e o intelecto [Verstand], ao contrário, superior, porque a sensibilidade só dá ao pensamento o mero material [Stoff], ao passo que o intelecto dispõe [disponirt] sobre esse material e o submete a regras ou conceitos (Log: AA 09, 36).

Prosseguindo em sua caracterização, Kant indica quais são as representações elementares com as quais lidam cada uma das faculdades intelectuais do ânimo:

A Lógica geral está dividida sobre um plano que se ajusta exatamente à divisão das faculdades superiores do conhecimento [oberen Erkenntnisvermögen]. São estas o entendimento [Verstand], a faculdade do juizo [Urteilskraft] e a razão [Vernunft]. Essa doutrina trata, pois, na sua analítica, de conceitos, juizos e raciocínios (...) $(K r V: \mathrm{B} 169)$.

Para Kant, o entendimento, também denominado de faculdade das regras [Vermögen der Regeln], é responsável por fornecer tanto conceitos puros (categorias), como conceitos sensíveis, sejam a priori (matemáticos) ou a posteriori (empíricos) e relacionar tais conceitos entre si, em séries de subordinação entre conceitos inferiores e superiores (Log: AA 09, 96 e ss.), que permite, em última instância, a formulação de juízos universais que servem de premissa maior em ilações da razão ( $K r V$ : A304/B360). Já a faculdade do juízo é responsável por ordenar conceitos em representações judicativas (juízos), cujos modos elementares consistem no que Kant denomina de funções lógicas ( $K r V$ : A68/B93), tendo sempre determinadas proposições fundamentais [Grundsätzen] como referência fundamental de sua aplicação a objetos da intuição sensível. Deste modo, Kant entende que a faculdade do juízo é a capacidade de discernir sobre a adequada aplicação de conceitos e juízos a casos particulares dados na intuição, ou seja, de decidir se algo na natureza se encontra ou não subordinado a eles:

Se é definido o entendimento em geral [überhaupt] como a faculdade das regras, a faculdade do juízo será a capacidade de subsumir sob regras, isto é, de discernir se algo se encontra subordinado a dada 
regra (casus datae legis) ou não (KrV: A132/B171).

Numa etapa seguinte, o entendimento e a faculdade do juízo colaboram na formulação dos juízos que serão logicamente encadeados pela razão nas inferências, que é justamente sua especificidade no conjunto das faculdades intelectuais. Neste caso, cabe à faculdade do juízo proporcionar os juízos particulares (premissa menor) que subsumem um determinado conhecimento à condição de uma regra, regra esta que o entendimento tem a responsabilidade de proporcionar e que consiste sempre em juízos universais das inferências da razão (premissa maior). A razão então, servindo-se destas duas representações judicativas proporcionadas pelo entendimento e pela faculdade do juízo, finalmente as conecta mediante a determinação do conhecimento (termo menor) pelo predicado da regra (termo maior), derivando um terceiro juízo (conclusão) logicamente inferido das referidas premissas ( $K r V$ : A304/B360). A razão é também denominada de faculdade dos princípios [Vermögen der Prinzipien], sendo a responsável por "unificar as regras do entendimento mediante princípios" ( $K r V$ : A302/B359), ou seja, "encontrar, para o conhecimento condicionado do entendimento, o incondicionado pelo qual se lhe completa a unidade" (KrV: A307/B364).

Queremos investigar a partir de agora em que medida esta concepção kantiana sobre as faculdades do ânimo pode contribuir na compreensão da classificação dos distintos graus do conhecimento inicialmente apresentados. Como se pode notar, o próprio modo pelo qual os graus de conhecimento são descritos indica que eles estão numa estreita articulação provavelmente fundada em critérios que justificam sua crescente complexidade. Vamos destacar inicialmente os pontos essenciais deste relacionamento para, a partir disso, considerarmos os sete graus sob o ponto de vista da distinção entre o saber dos animais e o conhecimento dos seres humanos. Mostraremos ainda, no decorrer da argumentação, que não por acaso toda esta discussão está intimamente relacionada também com a distinção kantiana entre dois tipos de objetos para nós, os aparecimentos [Erscheinungen] e os fenômenos [Phaenomena], questão esta que temos 
tratado detalhadamente em trabalhos anteriores (CALÁBRIA, 2003, 2004, 2006 e 2011$)^{3}$.

\section{Os graus de conhecimento segundo a colaboração entre as faculdades do ânimo}

O fato de que a série começa com "representar-se algo", vindo logo em seguida o "representar-se algo com consciência" (denominado de "perceber"), permite inferir que a distinção entre estes dois primeiros graus repousa precisamente na ausência de consciência no primeiro grau. O grau seguinte é descrito como o "representar-se algo pela comparação com outras coisas" (denominado de "saber"). Neste caso, o elemento inusitado que agora surge consiste na comparação com outras coisas, o que permite por um lado inferir que os graus anteriores, o perceber e o representar, devem ser realizados sem a comparação com outras coisas, estando resumidos na representação, consciente ou não, de algo simplesmente isolado. Porém, falta menção explícita à presença ou não de consciência neste terceiro grau. No entanto, vemos que a descrição do grau seguinte sana imediatamente esta dúvida, pois consiste no "saber com consciência" (denominado de "conhecer"). Assim, sendo apresentada a consciência como o elemento distintivo entre o conhecer e o saber, temos de inferir que no saber a consciência está ausente. Por outro lado, como o conhecer é descrito em termos de um "saber com consciência" e se no saber há comparação com outras coisas, concluímos que no conhecer também há esta comparação.

Isto permite descrever e distinguir os quatro primeiros graus mediante um quadro esquemático que torna evidente sua bem estruturada classificação fundada na presença ou ausência das características da "consciência" e "comparação":

3 O que nos despertou para esta questão foi o seguinte trecho presente na edição A (1781) da primeira Crítica: "Chamam-se fenômenos as manifestações sensíveis na medida em que são pensadas como objetos, segundo a unidade das categorias" [Erscheinungen, sofern sie als Gegenstaende nach der Einheit der Kategorien gedacht werden, heissen Phaenomena] (KrV: A248) 
QUADRO 1: Os quatro graus de conhecimento

\begin{tabular}{|l|c|c|}
\hline \multicolumn{1}{|c|}{ Grau } & consciência & comparação \\
\hline $\left.1^{\circ}\right)$ representar-se & sem & sem \\
\hline $\left.2^{\circ}\right)$ perceber & com & sem \\
\hline $\left.3^{\circ}\right)$ saber & sem & com \\
\hline $\left.4^{\circ}\right)$ conhecer & com & com \\
\hline
\end{tabular}

Já que estes quatro primeiros graus de conhecimento podem ser tratados como estando confinados ao domínio das representações sensiveis, será conveniente deixarmos para considerar os três últimos graus mais adiante, concentrando-nos no momento na discussão sobre a construção dos graus de conhecimento antes da intervenção de representações intelectuais ou discursivas. Como podemos facilmente constatar, isso representa justamente o divisor de águas que Kant, assim como em geral a tradição filosófica, costuma utilizar na explicação da diferença essencial que há entre o saber acessível aos animais e o conhecimento que os seres humanos podem alcançar ${ }^{4}$. Antes de tratarmos das informações suplementares que Kant apresenta durante a descrição destes quatro primeiros graus de conhecimento, relacionadas ao fato de que a comparação se dá segundo a identidade ou a diversidade e ao fato de que os animais [Thiere] (ou seja, os não racionais) têm a capacidade de saber dos objetos, mas não de conhecê-los, é oportuno fazer neste ponto outra conjectura significante, que diz respeito à relação entre o segundo e terceiro graus.

De fato, como nesta classificação dos quatro primeiros graus de conhecimento, Kant utiliza como critérios de caracterização os aspectos que concernem à "consciência" e à "comparação" das representações, e dado que o segundo grau possui apenas um destes aspectos (a consciência) e o terceiro grau possui apenas o outro aspecto (a comparação), então

4 É proveitoso mencionar a passagem do Crátilo em que Platão se referiu à diferença entre as relações que os seres humanos e os outros animais estabelecem com os objetos, ao dizer que apenas o homem é corretamente denominado de "ánthrōpos", pois ele é o único

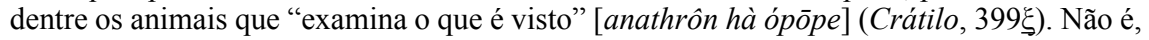
portanto, nova a constatação kantiana desta diferença entre o saber e o conhecer, mas sim, evidentemente, a concepção filosófica elaborada para explicá-la. 
estes conhecimentos somente podem ser colocados numa relação de subordinação, caso estes dois aspectos forem também passíveis de estabelecer uma relação de subordinação ou, pelo menos, serem tomados como pertencentes a distintos níveis de importância. Somente isso permite justificar que a comparação com outras coisas, que é característico do saber dos animais, pode conferir a este conhecimento um grau superior ao do "perceber", mesmo que aquele seja privado de consciência das representações. Deste modo, parece que o aspecto que tem maior peso no estabelecimento da hierarquia entre estes primeiros graus de conhecimento, é o da comparação de representações e não o da consciência delas.

Podemos estabelecer uma relação entre os graus de conhecimento e as capacidades do ânimo, considerando que a classificação dos vários tipos de conhecimento está plenamente de acordo com a caracterização que Kant faz sobre as capacidades do conhecimento, em particular na disciplinada e bem exemplificada descrição presente na "Antropologia" (1798), em que, como já indicamos acima, a sensibilidade é descrita como composta de duas partes, o sentido e a imaginação (Anth: AA 07,153) e o entendimento (lato sensu) é composto por entendimento (strito sensu), faculdade do juízo e razão (Anth: AA 07, 196-7). Assim sendo, o sentido é considerado como responsável apenas por receber passivamente a multiplicidade de representações intuitivas, dadas então de modo disperso e isolado ( $K r V$ : A120), o que pode ocorrer tanto consciente quanto inconscientemente (Anth: AA 07, 135-7), enquanto que algo bem diferente concerne à imaginação, à qual pertence a habilidade de espontaneamente efetuar a reunião desta multiplicidade de representações intuitivas dadas aos sentidos, ou seja, sintetizá-las devido a sua atividade autoral de formar figuras no espaço (Anth: AA 07, 174-6) e de associar intuições no tempo (Anth: AA 07, 176), o que corresponde aos três primeiros graus. $\mathrm{Na}$ sequência deste procedimento e para alcançar os graus mais elevados a partir do "conhecer", a intervenção das faculdades do entendimento (lato sensu) torna-se então necessária.

Como resultado inicial, vamos apresentar a correspondência direta que existe entre o que até aqui foi exposto sobre o "representar-se algo" e o "perceber algo" e aquilo que Kant descreve sobre as capacidades do ânimo, quando dá início às considerações sobre a capacidade de conhecer 
na "Antropologia". Podemos considerar estes dois primeiros graus de conhecimentos como tendo simplesmente nos sentidos a sua origem, sem que seja necessária a intervenção ou colaboração de qualquer outra capacidade do ânimo para obtê-los, já que o primeiro grau de conhecimento corresponde precisamente ao que é descrito na seção 5 da "Antropologia" e consiste no fato de frequentemente termos representações sem sermos delas conscientes, o que é exemplificado por Kant pelo "imenso campo de nossas sensações e intuições sensíveis” (Anth: AA 07, 135) provenientes de observações astronômicas, enquanto que o segundo grau corresponde ao que é descrito na seção 3 da "Antropologia" e recebe a denominação de "atenção", isto é, um esforço para não nos distrairmos das representações recebidas (Anth: AA 07, 131). Em ambos os casos, temos meramente a recepção de representações pelos sentidos, seja na ausência de sua consciência ("representar-se") ou na presença de sua consciência ("perceber").

Analogamente ao que fizemos acima em relação a estes dois primeiros graus de conhecimento, será apropriado tratarmos dos dois próximos graus em conjunto, pois ao descrever as características do "saber" e do "conhecer", Kant indica que há uma íntima relação também entre eles, embora desta vez ela seja mais complexa do que no caso anterior. De fato, a distinção entre o "representar-se" e o "perceber" concerne apenas à presença ou não da consciência das representações. O que encontraremos agora na distinção entre o terceiro e o quarto graus é que entra também em jogo a comparação com outras coisas e a presença ou não de operações discursivas.

Acontece que a comparação pode se dar meramente no domínio da sensibilidade. Um animal não racional, como um cão, por exemplo, ao qual Kant evidentemente não atribuiria capacidades intelectuais, pode então comparar objetos exclusivamente por meio da sua sensibilidade e assim identificar as figuras vistas em distintas ocasiões como sendo de uma pessoa, que ele sempre reconhece como a de seu "dono", assim como pode também diferenciá-la das figuras de outras pessoas vistas e que lhes são estranhas, de tal modo que tanto aquela identificação como esta diferenciação também pode ser realizada mediante outros sentidos, como costuma acontecer pelo olfato e pela audição. Entendemos que é a este tipo de conhecimento, ou reconhecimento sensível, que Kant chama de "saber" [kennen]. 
Porém, algo bem distinto ocorre a partir de então e, para que o argumento de Kant faça sentido daqui em diante, parece necessário fazermos uma análise mais acurada sobre a noção de consciência. De fato, para que haja consciência da percepção de algo, basta o esforço da atenção voltada à representação correspondente, como mencionamos logo acima (Anth: AA07, 131) e, neste caso, tal representação pode resumir-se a uma sensação ou uma intuição sensível resultante da afecção dos sentidos.

No caso do quarto grau, ou seja, o "conhecer" ou "saber algo com consciência", é preciso que a partir de agora a atenção seja voltada não apenas para a mera sensação ou intuição sensível que passivamente nos afeta, já não lidamos mais apenas com a percepção de uma representação, assim como não lidamos mais apenas com a comparação de representações que acaba produzindo o saber, já que neste caso não há nem sequer a consciência. A partir de agora entra em cena um outro tipo de consciência, visto que a atenção deve passar a dirigir-se não mais para representações que passivamente nos afetam, mas para o saber que foi ativamente elaborado, isto é, não mais para o produto da receptividade do sentido, mas para o produto da espontaneidade do entendimento, pois o saber, enquanto tal, já é um produto da atividade das capacidades do ânimo. Resumindo, aquilo para o que passamos a voltar a nossa atenção e do que nos tornamos conscientes não é mais o objeto dado da intuição sensível, mas o saber produzido sobre o objeto da intuição sensível. Isto é bem característico da distinção kantiana entre apercepção (que é intelectual) e sentido interno (que é sensível), aquele relacionado ao que nós, seres humanos, fazemos e este relacionado ao que sentimos (Anth: AA 07, 161).

É sintomática a advertência feita por Kant no quarto grau de conhecimento aos animais e sua capacidade de saber algo, descrito como a capacidade de não apenas ter representações (certamente intuitivas), mas ainda de percebê-las, o que implica a posse de algum tipo de consciência, nem que seja empírica e subjetiva e que não implica na posse de autoconsciência. A explícita menção, presente no terceiro nível (o do saber), à comparação das representações é um forte indício de que tais animais possuem habilidades que extrapolam o mero âmbito da receptividade dos sentidos (o simples representar ou perceber) e manifesta, além disso, uma capacidade ativa de relacionar ou associar representações que é típica da 
faculdade da imaginação. Então, de acordo com a filosofia kantiana o saber dos animais deve resultar exclusivamente de sua sensibilidade, composta, como a nossa, de sentidos e imaginação. Aos animais não racionais são acessíveis apenas os três primeiros graus de conhecimento, já que eles não possuem capacidades intelectuais de onde se originam as regras de unidade conceitual, mas somente a capacidade passiva de receber representações sensíveis (como o nosso sentido), e uma capacidade ativa de comparar tais representações (como a nossa imaginação), operando espontaneamente sínteses autônomas como as da apreensão e da reprodução (formação e associação, respectivamente), mas não as heterônomas como as da recognição (esquematismo). Este saber, próprio dos animais, provém da simples sensibilidade e consiste na capacidade de construir objetos sensíveis pela reunião da multiplicidade desconectada em percepções de objetos no espaço e associá-las a outras percepções no tempo, resultando num saber apenas subjetivo e circunstancial de aparecimentos. Com isso, Kant retira dos animais não racionais a possibilidade de terem acesso aos fenômenos [Phaenomena], que são os objetos típicos do conhecer, ou seja, os objetos próprios da experiência, considerada como "um produto empírico do entendimento" ( $\mathrm{KrV}$ : A98):

Por isso mediante a intuição as categorias não nos fornecem conhecimento algum das coisas senão apenas através de sua aplicação à intuição empírica, isto é, servem só à possibilidade do conhecimento empírico [empirischer Erkenntnis]. Este chama-se, porém, experiência [Erfahrung] (KrV: B147)

Os fenômenos somente podem resultar das operações sintéticas heterônomas que a imaginação opera no âmbito do esquematismo, unificando os aparecimentos sob a direção de regras conceituais ( $K r V$ : A146/B186), de onde surgem estes objetos (conceitualmente) determinados da nossa intuição empírica que, em conjunto, compõem a natureza (natura materialiter spectata) ( $\mathrm{KrV}$ : B163) e que, por estarem fundadas em última instância na unidade categorial, apresentam uma "necessária conformidade à lei (como natura formaliter spectata)" (KrV: B165). 


\section{Conclusão}

Não surpreende muito o fato de Kant utilizar o termo "conhecimento" de modo tão lato nesta classificação dos seus sete graus. Se bem que, a rigor, encontramos na primeira Crítica uma definição muito mais estrita deste termo na qual é dito que "no significado próprio do termo" ( $K r V$ : A78/B103), conhecimento designa o resultado do processo que envolve três etapas conjuntas da representação empírica dos aparecimentos: (i) a percepção pelos sentidos, (ii) a associação pela imaginação e (iii) a recognição pela apercepção ( $K r V$ : A 115), em diversas passagens desta e de outras obras este termo é empregado de modo bem mais amplo, como na própria Crítica da razão pura quando afirma que "fora da intuição, não há outro modo de conhecer senão por conceitos" ( $K r V$ : B92-3), considerando como sendo conhecimento tanto a intuição como o conceito separadamente. O que esta rica classificação dos conhecimentos indica é que, caso queiramos nos referir de modo mais preciso ao conhecimento que é acessível especificamente aos seres racionais finitos, como os humanos, devido precisamente à posse de capacidades intelectuais (discursivas), devemos relacioná-lo exclusivamente aos quatro últimos graus desta série, cujos objetos correspondentes recebem a denominação de fenômenos, enquanto que, aos outros três graus de conhecimento iniciais corresponderiam apenas objetos denominados de aparecimentos que são construídos apenas por meio das duas partes da sensibilidade (sentido e imaginação) e dos quais se obtém no máximo um saber não discursivo.

Notamos ao final que as concepções de Kant sobre os graus de conhecimento e sobre as capacidades do ânimo não apenas são conciliáveis, mas que se complementam e iluminam reciprocamente. Vimos que ao levar em conta as especificidades descritas na Lógica Jäsche para cada um dos sete tipos de conhecimento e das relações que há entre eles, notamos que tudo isto guarda uma significativa correspondência com as características, tarefas e operações que Kant, no conjunto de sua obra, sistematicamente credita a cada uma das capacidades do ânimo e que a distinção que temos sustentado existir na filosofia de Kant entre os dois tipos de objetos para nós encaixa-se de modo cogente em sua refinada doutrina. 


\section{Referências}

CAIMI, M. Comments on the Conception of Imagination in the Critique of Pure Reason. In: INTERNATIONALEN KANT-KONGRESSES: RECHT UND FRIEDEN IN DER PHILOSOPHIE KANTS, 10., 2005, São Paulo. Akten ... Berlin: De Gruyter, 2008. p. 39-50. Organizado por V. Rohden, R. R. Terra, G. A. de Almeida, M. Ruffing., v. 1.

- La imaginación en la Antropología en sentido pragmático. Estructura del texto y estructura del concepto. In: LERNER, R. R. P. de; LOBEIRAS, M. J. V. (Hg.). La razón y sus fines. Elementos para una antropología filosófica en Kant, Husserl y Horkheimer. Hildesheim: Georg Olms, 2013. p. 29-53.

CALÁBRIA, O. P. A imaginação de Kant e os dois objetos para nós (...). 2011. Tese (Doutorado em Filosofia) - Departamento de Filosofia da FAFICH, Universidade Federal de Uberlândia, Belo Horizonte, 2011.

. A distinção kantiana entre aparecimento e fenômeno. Kant

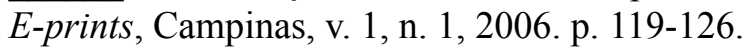

. Para Kant, o que aparece simplesmente não é fenômeno. In: COLÓQUIO DE HISTÓRIA DA FILOSOFIA DA UNESP, 1., 2004, Marília. Caderno de Resumos ... Marília: Unesp, 2004.

. Elementos fundamentais da Analítica transcendental de Kant. 2003. ?f. Dissertação (Mestrado em Filosofia) - Departamento de Filosofia do IFCH, Universidade de Campinas, Campinas, 2003.

HEIDEGGER, M. Kant und das Problem der Metaphysik. Gesamtausgabe. Bd.3. [1929] Frankfurt am Main: Vittorio Klostermann, 1991.

KANT, I. Kants gesammelte Schriften. Hrsg. von der Königlich Preussischen Akademie der Wissenschaften zu Berlin. Berlin: G. Reimer (Walter de Gruyter). [1900 - ss] (1968) AA (01 - 29).

. Werke: Kritik der reinen Vernunft (A). [1781]. (1968) AA 03.

. Werke: Kritik der reinen Vernunft (B) [1787]; Prolegomena; Grundlegung zur Metaphysik der Sitten [1783]; Metaphysische Anfansgrunde der Naturwissenschaft [1786]. (1968) AA 04.

. Crítica da razão pura. Tradução de Valério Rohden e Udo Baldur Moosburger. São Paulo: Abril Cultural, [1787] 1987. 
. Crítica da razão pura. Tradução de Manuela P. dos Santos e Alexandre F. Morujão. Lisboa: Calouste Gulbenkian, [1781 e 1787] 1997. . Prolegômenos. Tradução de Tania Maria Bernkopf [1783]. São Paulo: Abril Cultural, 1974.

. Antropologia de um ponto de vista pragmático. Tradução de Clélia Aparecida Martins. São Paulo: Iluminuras, [1798b] 2009.

. Anthropology, History, and Education. ZÖLLER, G.; LOUDEN, R. B. (Ed.). The Cambridge Edition of the Works of Immanuel Kant. Cambridge: Cambridge University Press, [1798b] 2007. p. 227-429.

. Werke: Logik. Physische Geographie, Paedagogik. (1968) AA 09. . Lógica. Manual dos cursos de lógica geral = Logik, ein Handbuch zu Vorlesungen / Immanuel Kant. Tradução e apresentação e guia de leitura de Fausto Castilho. Uberlândia: EDUFU; Campinas: IFCH - UNICAMP [1800], 1998. (Texto bilíngüe).

. Lógica. Tradução de Guido de Almeida. Rio de Janeiro: Tempo Brasileiro, [1800] 1992.

.Vorlesungen: Vorlesungen über Metaphysik und Rationaltheologie. (1968). AA 28.

LONGUENESSE, B. Kant et le pouvoir de juger: sensibilite et discursivite dans l'analytique transcendentale de la Critique de la raison pure. Paris: Presses Univ. de France, 1993.

. Kant and the Capacity of Judge: Sensibility and Discursivity in the Transcendental Analytic of the Critique of Pure Reason. 2. ed. Translated from the French by Charles T. Wolfe. [1998]. Princeton: Princeton University Press, 2000.

Press, 2005.

. Kant on the Human Standpoint. New York: Cambridge University

MAKKREEL, R. A. Imagination and interpretation in Kant: the hermeneutical import of the Critique of Judgment. [1990]. Chicago: The University of Chicago Press, 1994.

Data de registro:05/06/2013

Data de aceite: 08/07/2013 